\title{
Riskier-than-expected occlusive treatment of ruptured posterior communicating artery aneurysms: treatment and outcome of 620 consecutive patients
}

\author{
Justiina Huhtakangas, MD, Martin Lehecka, MD, PhD, Hanna Lehto, MD, PhD, \\ Behnam Rezai Jahromi, MD, Mika Niemelä, MD, PhD, and Riku Kivisaari, MD, PhD \\ Helsinki University Hospital, University of Helsinki, Finland
}

\begin{abstract}
OBJECTIVE Occlusive treatment of posterior communicating artery (PCOA) aneurysms has been seen as a fairly uncomplicated procedure. The objective here was to determine the radiological and clinical outcome of patients after PCoA aneurysm rupture and treatment and to evaluate the risk factors for impaired outcome.
\end{abstract}

METHODS In a retrospective clinical follow-up study, data were collected from 620 consecutive patients who had been treated for ruptured PCoA aneurysms at a single center between 1980 and 2014. The follow-up was a minimum of 1 year after treatment or until death.

RESULTS Of the 620 patients, $83 \%$ were treated with microsurgical clipping, $8 \%$ with endovascular coiling, $2 \%$ with the two procedures combined, $1 \%$ with indirect surgical methods, and $6 \%$ with conservative methods. The most common procedural complications were treatment-related brain infarctions (15\%). The occurrence of artery occlusions $(10 \% \mathrm{mi}-$ crosurgical, $8 \%$ endovascular) was higher than expected. Most patients made a good recovery at 1 year after aneurysmal subarachnoid hemorrhage (modified Rankin Scale [mRS] score 0-2: 386 patients [62\%]). A fairly small proportion of patients were left severely disabled (mRS score 4-5: 27 patients [4\%]). Among all patients, $20 \%$ died during the $1 \mathrm{st}$ year. Independent risk factors for an unfavorable outcome, according to the multivariable analysis, were poor preoperative clinical condition, intracerebral or subdural hematoma due to aneurysm rupture, age over 65 years, artery occlusion on postoperative angiography, occlusive treatment-related ischemia, delayed cerebral vasospasm, and hydrocephalus requiring a shunt.

CONCLUSIONS Even though most patients made a good recovery after PCoA aneurysm rupture and treatment during the 1st year, the occlusive treatment-related complications were higher than expected and caused morbidity even among initially good-grade patients. Occlusive treatment of ruptured PCoA aneurysms seems to be a high-risk procedure, even in a high-volume neurovascular center.

https://thejns.org/doi/abs/10.3171/2018.4.JNS18145

KEYWORDS mortality; outcome; posterior communicating artery aneurysm; subarachnoid hemorrhage; treatment; vascular disorders

$\mathrm{P}$ OSTERIOR communicating artery (PCoA) aneurysms along the internal carotid artery (ICA; incidence range among ruptured intracranial aneurysms $13 \%-$ $25 \%)^{11,23,27,38}$ are often seen as fairly uncomplicated lesions that are suitable for both neurosurgical and endovascular treatment. Since the International Subarachnoid Aneurysm
Trial (ISAT), the treatment of ruptured anterior circulation aneurysms has shifted toward endovascular treatment. ${ }^{27}$ However, a large number of patients have been treated surgically as well. Even though these lesions are encountered frequently, there are few clinical studies on the outcome of patients with ruptured PCoA aneurysms., ${ }^{9,37,39}$

ABBREVIATIONS aSAH = aneurysmal subarachnoid hemorrhage; DSA = digital subtraction angiography; $E V D=$ extraventricular drain; $H H=H u n t$ and Hess; ICA = internal carotid artery; $I \mathrm{CH}=$ intracerebral hematoma; IVH = intraventricular hemorrhage; $\mathrm{MCA}=$ middle cerebral artery; $\mathrm{mRS}=$ modified Rankin Scale; ONP = oculomotor nerve palsy; $\mathrm{PCOA}=$ posterior communicating artery; $\mathrm{SDH}=$ subdural hematoma; $\mathrm{VIF}=$ variance inflation factor.

SUBMITTED January 17, 2018. ACCEPTED April 5, 2018.

INCLUDE WHEN CITING Published online October 19, 2018; DOI: 10.3171/2018.4.JNS18145. 
There are challenges related to the treatment of ruptured PCoA aneurysms. When ruptured, they have the potential to cause severe aneurysmal subarachnoid hemorrhage (aSAH) with intraventricular hemorrhage (IVH) and temporal intracerebral hematoma (ICH) or subdural hematoma (SDH) and oculomotor nerve palsies (ONPs). $3,7,13,15,20,26,35,42$ Nearly one-third of the ruptured aneurysms lie beside the fetal or dominant PCoA, which can be compromised. ${ }^{6,15,21}$ And the most common orientation, a posterior orientation of the dome, can be associated with higher treatment-related complications than more lateral orientations because of the limited visualization in microsurgical treatment. ${ }^{9,15}$

Our goal was to evaluate how patients recover after the rupture of a PCoA aneurysm and the treatment challenges related to this aneurysm location. We determined the radiological and clinical outcomes of these patients after microsurgical or endovascular treatment and evaluated the potential risk factors related to an impaired outcome.

\section{Methods \\ Study Cohort}

This is a retrospective clinical follow-up study. The cohort consists of 620 consecutive aSAH patients treated for a ruptured PCoA aneurysm at a single neurosurgical center between 1980 and 2014 (catchment area 1.8 million). Seven patients were excluded because they had been treated primarily at other hospitals. Endovascular therapy has been available in our department since 1991.

\section{Follow-Up Data}

The patients' clinical and radiological data were reviewed for relevant information concerning the primary treatment period and the follow-up. An experienced radiologist and a neurosurgeon collected the data and reviewed all the images.

Preoperative images, including brain CT and CTA, digital subtraction angiography (DSA), or MRA images, were analyzed. Intraventricular hemorrhage was defined as any blood in the ventricular system (excluding thin layers of blood in the occipital horns several days after the ictus), and SDH was defined as any blood in the subdural space. Intracerebral hematoma referred to any intracerebral hematoma with a minimum diameter of $10 \mathrm{~mm}$ (mean maximal diameter $29 \mathrm{~mm}$, range $10-79 \mathrm{~mm}$ ). We also evaluated the radiological features of the ruptured PCoA aneurysms. Preoperative hydrocephalus referred to dilated ventricles and symptoms such as a decreased level of consciousness requiring an extraventricular drain (EVD).

Altogether, 23 neurosurgeons or neurointerventionalists performed the occlusive treatment for the ruptured PCoA aneurysms directly via microsurgical clipping, endovascular coiling, or a combination of these two techniques, or indirectly with carotid ligation or trapping. For all patients with no contraindications, postoperative angiography (DSA or CTA), in addition to the postoperative brain CT, was conducted on the day of or the day following the procedure. The occlusion rate of the treated aneurysm, as well as the clinical and radiological complications, was reported. Probable causes of any ischemic complications were classified. Diagnosis of a delayed cerebral vasospasm was based on clinical and radiological findings. Clinically, it was classified as severe if both deterioration of consciousness and focal deficits were symptoms. Patients requiring a shunt suffered from symptomatic hydrocephalus postoperatively (EVD or no EVD previously).

Patients who received endovascular treatment had routine DSA at 6 months. Other imaging evaluations were based on individual needs. All patients had a postoperative clinical checkup at 3-6 months after the aSAH, and patients were followed up for a minimum of 1 year (most) or until death. If the patient had a favorable recovery at the early checkup, the 1-year checkup was not routinely scheduled.

The Fisher scale was used to grade the severity of bleeding, the Hunt and Hess (HH) scale to rate clinical condition, and the modified Rankin Scale (mRS) to score outcome. ${ }^{8,17,31}$ Good outcome was defined as an mRS score $0-2$, and unfavorable outcome as an mRS score $>2$. All deaths were verified from the Population Register Centre, and death certificates were acquired from the national statistics center. Twenty-six patients (4\%) were lost during the follow-up after discharge but had not died during the 1st year after aSAH. As this study is a hospital- and university-approved, register-based study, specific patient consents were not necessary.

\section{Statistical Analysis}

The different categorical variables possibly related to outcome and their statistical significance were evaluated using Pearson's chi-square test ( $p<0.05$, using 95\% confidence intervals). Multivariable analyses with logistic regression (Microsoft R Open, version 3.4.3, http://mran. microsoft.com/rro) were conducted to identify independent risk factors for an unfavorable outcome and to estimate the odds of an impaired outcome with the variables identified as significant in the univariable analysis. In addition, likelihood ratio tests were used for variables with multiple levels or categories.

We chose patient-related, preoperative, and postoperative parameters potentially related to outcome and evaluated their effect on clinical outcome at the 1-year followup. Variables included in the univariable analysis were as follows: patient age group, preoperative clinical condition, severity of initial bleeding (IVH or ICH or SDH related to aSAH), aneurysm size, preoperative hydrocephalus, timing of operation, delay in treatment, rebleeding before treatment, bleeding during aneurysm treatment, artery occlusion on postoperative angiography, treatment-related brain infarction, symptomatic delayed cerebral vasospasm, and hydrocephalus requiring a shunt. Since some of the parameters are related to each other (e.g., severity of bleeding and clinical condition), we calculated the collinearity of the variables using the variance inflation factor (VIF) and made sure that their correlation was not so high $(>10)$ that it would affect the results. The VIFs of all the chosen parameters were $<2$. Finally, the STROBE (Strengthening the Reporting of Observational Studies in Epidemiology) checklist was implemented as the reporting guideline. 
TABLE 1. Characteristics of 620 aSAH patients with ruptured PCoA aneurysms

\begin{tabular}{lccc}
\hline \multicolumn{1}{c}{ Parameter } & Female & Male & $\begin{array}{c}\text { Overall } \\
(\% \text { total })\end{array}$ \\
\hline No. of patients & $468(75 \%)$ & $152(25 \%)$ & 620 \\
\hline Mean age in yrs & 55 & 49 & 54 \\
\hline Clinical condition prior to aSAH & & & \\
$\quad$ Able to work & 398 & 142 & $540(87)$ \\
Independent & 63 & 8 & $71(11)$ \\
Little help & 6 & 2 & $8(1)$ \\
Continuous help & 1 & 0 & $1(<1)$ \\
\hline Multiple aneurysms & 163 & 38 & $201(32)$ \\
\hline ONP & 82 & 20 & $102(16)$ \\
\hline Fisher grade & & & \\
1 & 35 & 15 & $50(8)$ \\
2 & 52 & 15 & $67(11)$ \\
3 & 101 & 38 & $139(22)$ \\
4 & 220 & 60 & $280(45)$ \\
Not verified & 60 & 24 & $84(14)$ \\
\hline Preop HH grade & & & \\
I & 75 & 28 & $103(17)$ \\
II & 170 & 57 & $227(37)$ \\
III & 99 & 35 & $134(22)$ \\
IV & 81 & 19 & $100(16)$ \\
V & 42 & 13 & $55(9)$ \\
Data missing & 1 & 0 & $1(<1)$ \\
\hline Active treatment & 438 & 144 & $582(94)$ \\
\hline Conservative treatment & 30 & 8 & $38(6)$ \\
\hline
\end{tabular}

\section{Results}

\section{Patient Characteristics}

The mean patient age was 54 years (range 20-92, SD \pm 14 ), and there was a female predominance $(75 \%)$. Prior to aneurysm rupture, a large majority of patients had been able to work $(87 \%)$ or were independent, nonworking citizens (11\%). All the patients had suffered from aSAH caused by a ruptured PCoA aneurysm. Characteristics of the study population are shown in Table 1 . Features of the ruptured PCoA aneurysms appear in Table 2.

\section{Treatment of Ruptured PCoA Aneurysms}

Most patients (582 [94\%]) were actively treated, meaning that treatment was aimed at occlusion of the ruptured PCoA aneurysm. Treatment details and treatment-related complications are presented in Tables $2-4$. Since there is clear predominance of the microsurgical treatment, it is not reasonable to compare the different treatment methods. The distribution of the treatment methods reflects the department policy in that time period.

\section{Distribution of Treatment Methods}

Of the 620 ruptured aneurysms, $83 \%$ (517) were treated with microsurgical clipping, $8 \%$ (49) with endovascular coiling, $2 \%$ (10) with a combination of the two techniques, and $<1 \%$ (6) via indirect means using carotid ligation or trapping. Conservative treatment was chosen mainly be-
TABLE 2. Features of 620 ruptured PCoA aneurysms and methods of treatment

\begin{tabular}{lrr}
\hline \multicolumn{1}{c}{ Parameter } & No. & $\%$ Total \\
\hline Size & & \\
Small $(<7 \mathrm{~mm})$ & 186 & 30 \\
Medium $(7-14 \mathrm{~mm})$ & 315 & 51 \\
Large $(15-24 \mathrm{~mm})$ & 34 & 5 \\
Giant $(\geq 25 \mathrm{~mm})$ & 7 & 1 \\
Data missing & 78 & 13 \\
\hline Surface of dome & & \\
Irregular & 490 & 79 \\
Smooth & 63 & 10 \\
Not known & 67 & 11 \\
\hline Morphology & & \\
Saccular & 619 & 100 \\
Fusiform & 1 & $<1$ \\
\hline Microsurgical treatment & 523 & 84 \\
Clipping & 517 & 83 \\
Indirect method & 6 & 1 \\
\hline Endovascular treatment & 49 & 8 \\
\hline Combined treatment & 10 & 2 \\
\hline Conservative treatment & 38 & 6 \\
\hline Reason for conservative treatment & & \\
Poor condition & 22 & 4 \\
Old age & 2 & $<1$ \\
Refusal of other options & 3 & $<1$ \\
Other & 4 & $<1$ \\
Died before treatment & 7 & \\
\hline & & \\
\hline
\end{tabular}

cause of a patient's poor clinical condition on admission (38 [6\%]; Table 2). The attitude toward the treatment of poor-grade aSAH patients changed over the study period; after 2000 , a large portion of poor-grade patients have

TABLE 3. Ischemia due to occlusive treatment and other causes, grouped according to patient age

\begin{tabular}{|c|c|c|c|c|}
\hline \multirow[b]{2}{*}{ Parameter } & \multicolumn{3}{|c|}{ Age Group (no. of patients) } & \multirow{2}{*}{$\begin{array}{l}\text { Total No } \\
\text { (\% total) }\end{array}$} \\
\hline & $<50$ Yrs & $50-65$ Yrs & $>65 \mathrm{Yrs}$ & \\
\hline No. of patients & 232 & 232 & 118 & 582 \\
\hline \multicolumn{5}{|l|}{ Cause of ischemia } \\
\hline ICA or MCA occlusion & 9 & 6 & 0 & $15(3)$ \\
\hline $\begin{array}{c}\text { Fetal/dominant } \mathrm{PCoA} \\
\text { or } \mathrm{AChA} \text { occlusion }\end{array}$ & 1 & 4 & 6 & $11(2)$ \\
\hline Thalamic ischemia & 8 & 18 & 12 & $38(7)$ \\
\hline $\begin{array}{l}\text { Angiography-related } \\
\text { ischemia }\end{array}$ & 1 & 1 & 0 & $2(<1)$ \\
\hline Retraction injury & 4 & 6 & 4 & $14(2)$ \\
\hline Thromboembolic lesion & 1 & 6 & 2 & $9(2)$ \\
\hline $\begin{array}{l}\text { Initial bleeding-related } \\
\text { ischemia }\end{array}$ & 10 & 12 & 8 & $30(5)$ \\
\hline $\begin{array}{l}\text { Vasospasm-related } \\
\text { ischemia }\end{array}$ & 13 & 5 & 6 & $24(4)$ \\
\hline Unknown origin & 19 & 26 & 15 & $60(10)$ \\
\hline
\end{tabular}


TABLE 4. Most common complications of initial treatment period after PCoA aneurysm rupture

\begin{tabular}{|c|c|c|c|c|c|}
\hline \multirow[b]{2}{*}{ Parameter } & \multicolumn{4}{|c|}{ Treatment (no. of patients [\% total]) } & \multirow[b]{2}{*}{ Total No. (\% total) } \\
\hline & Microsurgical & Endovascular & Combined & Indirect Method & \\
\hline No. of patients & 517 & 49 & 10 & 6 & 582 \\
\hline Rebleeding before treatment & $113(22)$ & $9(18)$ & $3(30)$ & $1(17)$ & $126(22)$ \\
\hline Artery occlusion on postop angiography & $54(10)$ & $4(8)$ & $0(0)$ & $2(33)$ & $60(10)$ \\
\hline Occlusive treatment-related ischemia & $80(15)$ & $4(8)$ & $2(20)$ & $2(33)$ & $88(15)$ \\
\hline \multicolumn{6}{|l|}{ Postop infection } \\
\hline Meningitis & $31(6)$ & $3(6)$ & $1(10)$ & $0(0)$ & $35(6)$ \\
\hline Pneumonia & $133(26)$ & $17(35)$ & $5(50)$ & $1(17)$ & $156(27)$ \\
\hline Septicemia & $21(4)$ & $2(4)$ & $0(0)$ & $0(0)$ & $23(4)$ \\
\hline UTI & $139(27)$ & $15(31)$ & $1(10)$ & $1(17)$ & $156(27)$ \\
\hline Wound infection & $12(2)$ & $0(0)$ & $0(0)$ & $0(0)$ & $12(2)$ \\
\hline Pulmonary embolism & $7(1)$ & $0(0)$ & $0(0)$ & $0(0)$ & $7(1)$ \\
\hline Deep venous thrombosis & $8(2)$ & $0(0)$ & $0(0)$ & $0(0)$ & $8(1)$ \\
\hline Postop myocardial infarction & $6(1)$ & $1(2)$ & $2(20)$ & $0(0)$ & $9(2)$ \\
\hline Postop hematoma & $14(3)$ & $1(2)$ & $1(10)$ & $0(0)$ & $16(3)$ \\
\hline EVD-related hematoma & $10(2)$ & $2(4)$ & $0(0)$ & $0(0)$ & $12(2)$ \\
\hline Hydrocephalus requiring shunt & $77(15)$ & $9(18)$ & $3(30)$ & $0(0)$ & $89(15)$ \\
\hline Delayed vasospasm & $103(20)$ & $6(12)$ & $0(0)$ & $2(33)$ & $111(19)$ \\
\hline Death w/in $1 \mathrm{mo}$ & $49(9)$ & $7(14)$ & $2(20)$ & $3(50)$ & $61(10)$ \\
\hline
\end{tabular}

UTI = urinary tract infection.

been actively treated ( $\mathrm{HH}$ grade IV-V patients increased from $15 \%$ to $38 \%$ before and after the year 2000 , respectively; Fig. 1).

\section{Occlusion Rate and Additional Treatment}

Postoperative angiography (DSA or CTA) was performed in 95\% (551) of cases. There were differences in the radiological occlusion rates after the different treatment methods. Total occlusion was achieved in $90 \%$ of patients who had undergone clipping, $67 \%$ of those who had undergone endovascular treatment, and $100 \%$ of those who had been treated with the combined method.

The need for immediate additional treatment was $4 \%$ (19 cases) for clipped aneurysms and 12\% (6) for coiled aneurysms. In addition, seven coiled PCoA aneurysms were re-embolized during the 1st year of follow-up. Altogether, $27 \%$ of the coiled aneurysms required retreatment during the 1st year.

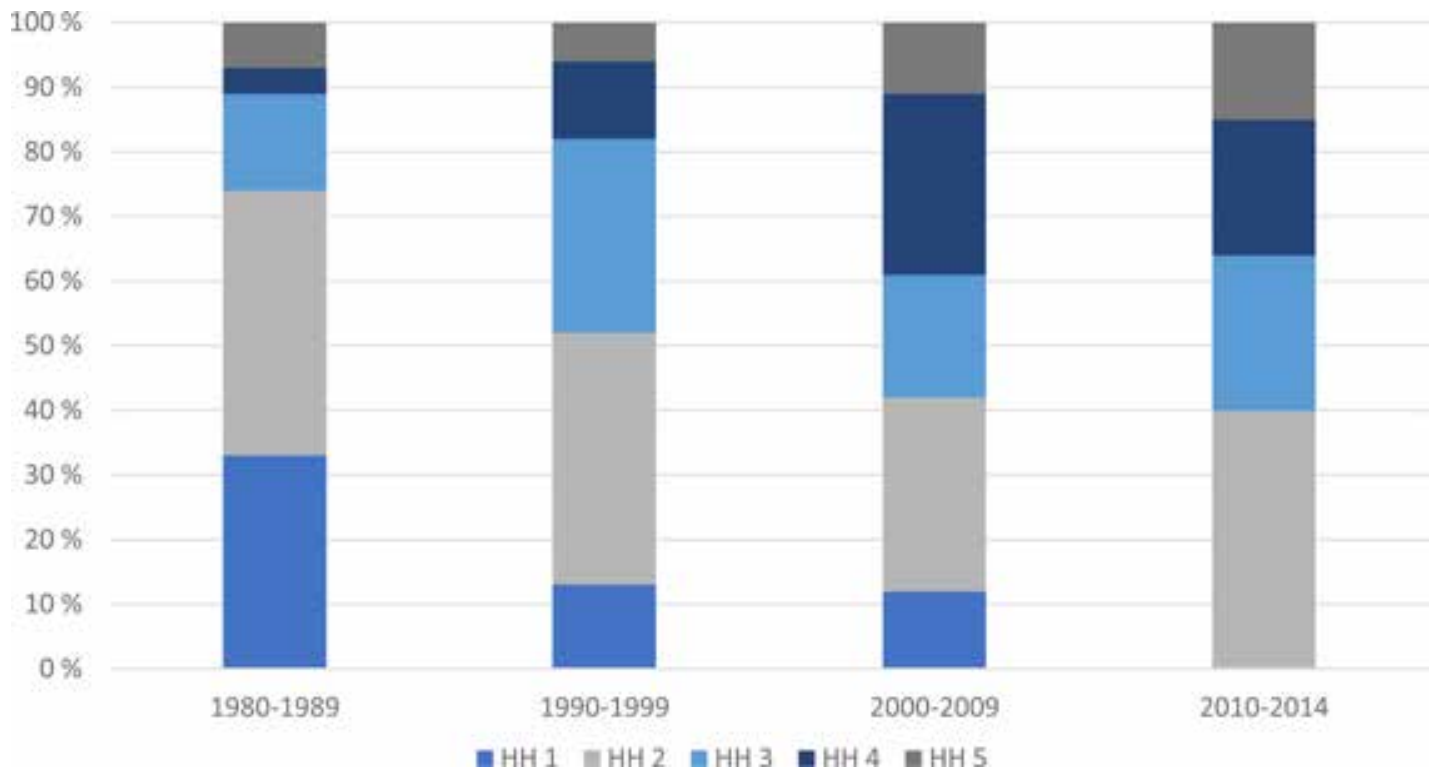

FIG. 1. Preoperative clinical condition ( $\mathrm{HH}$ grade) of aSAH patients after $\mathrm{PCOA}$ aneurysm rupture in different time periods. The $y$-axis represents the percentage of patients. 
TABLE 5. Outcomes of 620 consecutive patients after PCoA aneurysm rupture and treatment

\begin{tabular}{lcc}
\hline \multirow{2}{*}{ Parameter } & \multicolumn{2}{c}{ No. (\%) } \\
\cline { 2 - 3 } & At Discharge & At 1 Yr \\
\hline No. of patients & $620(100)$ & $594(96)$ \\
\hline mRS score & & \\
0, no symptoms & $0(0)$ & $158(25)$ \\
1, mild symptoms & $114(18)$ & $88(14)$ \\
2, slight disability but independent & $135(22)$ & $140(23)$ \\
3, disabled but able to walk & $100(16)$ & $54(9)$ \\
4, moderately severe disability & $58(9)$ & $13(2)$ \\
$\quad$ (unable to walk) & $128(21)$ & $14(2)$ \\
5, bedridden & $85(14)$ & $127(21)$ \\
6, death & & \\
Cause of death & $84(99)$ & $118(93)$ \\
Related to aSAH & $1(1)$ & $9(7)$ \\
Not related to aSAH &
\end{tabular}

\section{Procedural and aSAH-Related Complications}

The most common procedural complications were aneurysm occlusive treatment-related ischemic lesions $(15 \%)$ and artery occlusion on postoperative angiography (10\%; Table 4). Occlusive treatment-related ischemic lesions included small thalamic ischemia (7\%), occlusion or thrombosis of ICA or middle cerebral artery (MCA; $3 \%$ ), occlusion of fetal/dominant PCoA or anterior choroidal artery (2\%), thromboembolic lesions (2\%), retraction injuries $(2 \%)$, and other angiography-related ischemia $(<$ $1 \%$; Table 3).

Other aSAH-related complications included infections (pneumonia $27 \%$, urinary tract infection $27 \%$ ), symptomatic delayed cerebral vasospasm (19\%), and hydrocephalus requiring extraventricular drainage $(16 \%)$ or a shunt later on (15\%; Table 4). Most of the patients who died did so within the 1st month after aSAH (17\% of all patients).

Oculomotor nerve palsy was a typical symptom after PCoA aneurysm rupture: 16\% (102) of patients had ONP on admission. Follow-up data on oculomotor function were available for 44 patients (43\%), and $75 \%$ of them had full oculomotor nerve recovery. The remaining $25 \%$ had partial recovery and were often left with occasional diplopia.

\section{Outcome Data}

Recovery at 1 Year After Treatment

Most patients (386 [62\%]) made a good recovery (mRS score $0-2$ ) at 1 year after PCoA aneurysm rupture. Of the patients younger than 50 years old, $84 \%$ returned home after treatment and rehabilitation. Even those patients with severe disabilities at discharge usually made significant improvement neurologically during the 1 st year (mRS score 4-5: $30 \%$ at discharge vs $4 \%$ at 1 year; Table 5). A fairly small proportion of patients (27 [4\%]) were left severely disabled (unable to walk or bedridden, mRS score 4-5), and 127 patients died (21\%). Changes in outcomes in the different decades during follow-up are presented in Fig. 2.

\section{Mortality}

Among all the patients with ruptured PCoA aneurysms (both active and conservative treatment groups), 20\% (127) died during the 1st year. The most common cause of death was the initial aSAH (118 patients [93\%]). Those who died because of aSAH could be divided into subgroups according to the contributing factors: severe initial bleeding (42 patients [33\%]), additional brain infarction (33 [26\%]), delayed cerebral vasospasm (6 [5\%]), rebleeding (18 [14\%]),

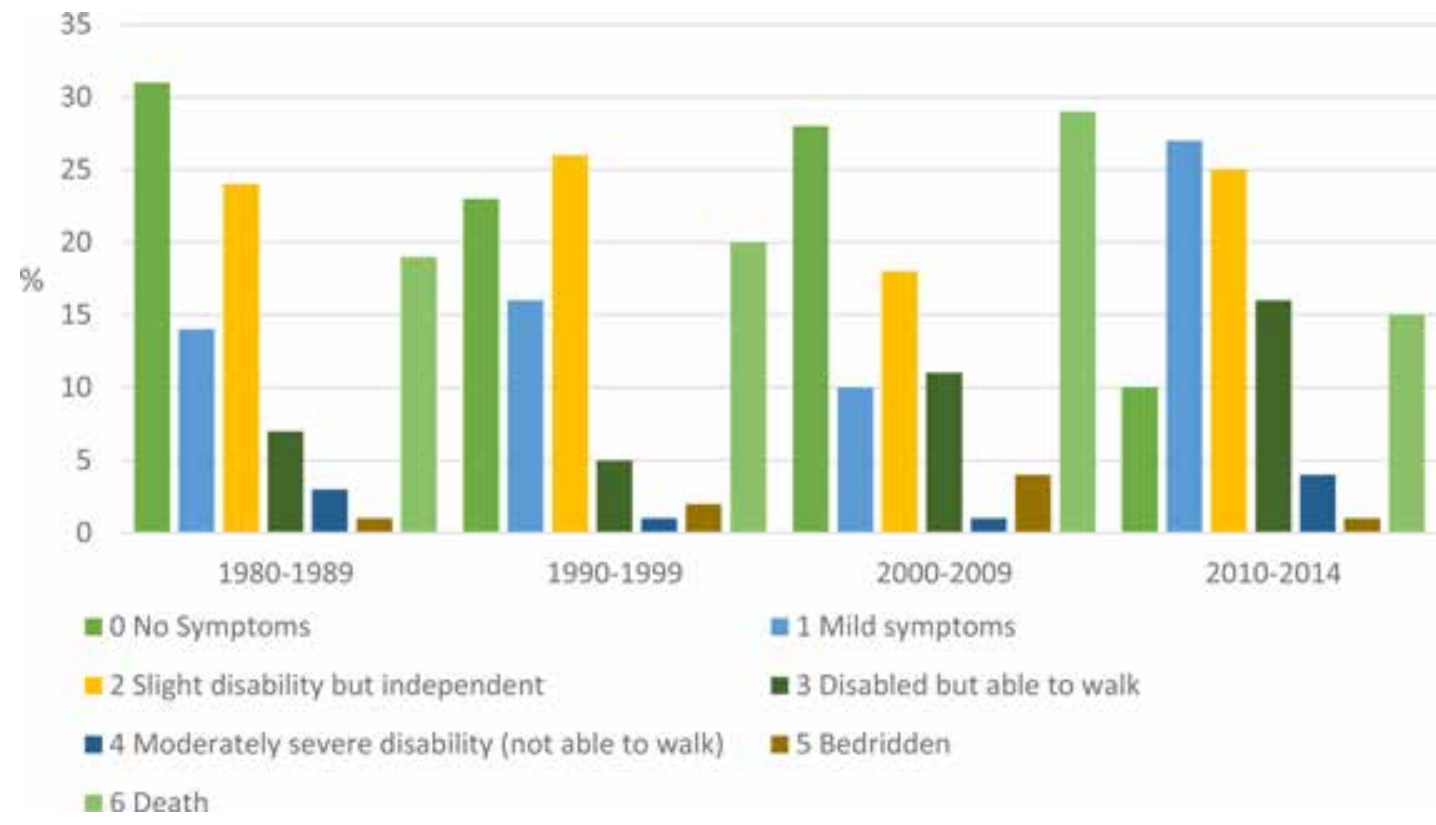

FIG. 2. Clinical outcome (mRS score) at 1 year after aSAH and treatment of a ruptured PCoA aneurysm at different time periods. The $y$-axis represents the percentage of patients. 
TABLE 6. Independent risk factors for unfavorable outcome ( $m R S$ score $>2$ ) at 1 year: results of multivariable analysis

\begin{tabular}{lcc}
\hline \multicolumn{1}{c}{ Factor } & $\begin{array}{c}\text { p Value, } \\
\text { Chi-Squared Test }\end{array}$ & OR \\
\hline Age group in yrs & $<0.001$ & \\
$\quad<50$ & & 1.0 \\
$50-65$ & & 1.7 \\
$\quad>65$ & & 7.2 \\
\hline Poor preop grade & $<0.001$ & \\
HH III & & 1.8 \\
HH IV-V & $<0.001$ & 2.5 \\
\hline ICH or SDH related to aSAH & $<0.001$ & 5.0 \\
\hline Artery occlusion on postop angiography & $<0.001$ & 2.0 \\
\hline Delayed cerebral vasospasm & $<0.001$ & 3.7 \\
\hline Occlusive treatment-related ischemia & $<0.001$ & 2.4 \\
\hline Hydrocephalus requiring shunt & & \\
\hline
\end{tabular}

and delayed other complication related to aSAH and poor condition $(19$ [15\%]). All patients who died because of rebleeding had been treated conservatively or with indirect surgical methods.

\section{Factors Related to Impaired Outcome}

After multivariable logistic regression, the independent risk factors for impaired outcome turned out to be poor preoperative clinical condition, older age, ICH or SDH after aneurysm rupture, artery occlusion on postoperative angiography, occlusive aneurysm treatment-related brain infarction, delayed cerebral vasospasm, and hydrocephalus requiring a shunt. The highest odds of an impaired outcome were related to 1) age over 65 years (OR 7.2), 2) artery occlusion on postoperative angiography (OR 5.0), 3) poor preoperative clinical grade $(\mathrm{HH}$ grade IV-V, OR 4.9), and occlusive treatment-related brain infarction (OR 3.7; Table 6).

\section{Age and Hydrocephalus After PCoA Aneurysm Rupture}

Less than half the patients with dilated ventricles on admission (248 [40\%]) needed extraventricular drainage to treat the condition $(100[16 \%])$. Nearly as many (90 patients [15\%]) received a permanent shunt later on. About half the patients requiring a shunt had received an EVD earlier (47 patients); the others developed hydrocephalus later on.

Post-aSAH hydrocephalus was more common among the elderly patients than among the younger age groups (permanent shunt: 7\%, 24\%, and 34\% of patients, respectively, for those aged $<50,50-65$, and $>65$ years). Both older age and hydrocephalus requiring a shunt were independently associated with higher odds of an impaired outcome (Table 6).

\section{Preoperative Clinical Condition}

A poor preoperative clinical condition (HH grade IV$\mathrm{V})$ was an independent risk factor for an impaired outcome. Nearly half of these poor-grade patients died (74 [49\%]). Some made a good recovery at 1 year (mRS score
0-2: 39 patients [26\%]; mRS score 3: 25 [17\%]). Patients with a good clinical grade after the bleeding were still exposed to occlusive aneurysm treatment-related risks. Treatment-related brain infarctions were also prominent among good-grade patients but were even more prominent among the poor-grade patients (Table 7).

\section{$\mathrm{ICH}$ or SDH After Aneurysm Rupture}

Patients with ICH (71 [11\%]) or SDH (24 [4\%]) had about a 2.5-fold elevated risk of an impaired outcome (Table 6). Intraventricular hemorrhage related to aSAH was not an independent risk factor. Patients with ICH or SDH or both were often in a poor clinical condition on admission (HH grade IV-V: 58 of those with hematomas [61\%]), and they were mainly treated surgically (79 [83\%]), which provided the possibility for hematoma removal when needed.

\section{Occlusive Treatment-Related Brain Infarctions}

Occlusive treatment-related brain infarctions were also prominent complications among young patients (Table 3 ). Of all actively treated PCoA patients, 10\% (60) had artery occlusion on postoperative angiography (Table 4). This complication was seen in both microsurgical and endovascular treatment groups (10\% and $8 \%$, respectively). A smaller number of patients (26 [4\%]) had postoperative brain infarctions related to main artery occlusion. Moreover, some of the deep thalamic infarctions (7\%) might be related to PCoA compromise, whereas others might be due to damage of small perforant arteries not visible on angiography. Even though there was some correlation between the artery occlusion group and the group with occlusive treatment-related infarctions, they were both estimated to be independent risk factors for an impaired outcome (Table 6).

\section{Delayed Cerebral Vasospasm and Ischemia}

Delayed cerebral vasospasm and ischemia (clinical symptoms and radiological findings) were detected and treated in $19 \%$ (111) of the actively treated patients. In about one-third of these patients (38), the vasospasm was classified as severe, with deterioration of consciousness and focal deficits. Only one-fifth of the patients who received treatment for vasospasm (23 [4\% of all patients]) developed visible ischemic lesions caused by the condition. However, it is possible that among those patients who had ischemic lesions of unknown origin (62 [11\% of treated patients]), some of the lesions were related to delayed cerebral vasospasm and ischemia but could not be verified.

\section{Discussion}

\section{Main Results}

Our results are from a large, consecutive series of patients with a ruptured PCoA aneurysm treated in a highvolume vascular neurosurgical unit. Most patients made a good recovery at 1 year, including many of those who had significant disabilities at discharge. However, a large proportion of patients had been in poor clinical condition initially, and occlusive treatment-related complications, 
TABLE 7. Occlusive treatment-related ischemia according to preoperative clinical condition of treated patients

\begin{tabular}{|c|c|c|c|c|c|}
\hline \multirow[b]{2}{*}{ Parameter } & \multicolumn{4}{|c|}{ Preop HH Grade (no. of patients [\%]) } & \multirow[b]{2}{*}{ Total No. $(\%)$} \\
\hline & $|-| \mid$ & III & IV & V & \\
\hline No. of patients & 326 & 130 & 94 & 32 & 582 \\
\hline \multicolumn{6}{|l|}{ Occlusive treatment-related ischemia } \\
\hline ICA or MCA occlusion & 7 & 6 & 2 & 0 & $15(3)$ \\
\hline Fetal/dominant PCoA or AChA occlusion & 1 & 1 & 6 & 3 & $11(2)$ \\
\hline Thalamic ischemia & 15 & 8 & 11 & 4 & $38(7)$ \\
\hline Angiography-related ischemia & 0 & 1 & 1 & 0 & $2(<1)$ \\
\hline Retraction injury & 8 & 4 & 2 & 0 & $14(2)$ \\
\hline Thromboembolic lesion & 1 & 2 & 5 & 1 & $9(2)$ \\
\hline Total & $32(10)$ & $22(17)$ & $27(29)$ & $8(25)$ & $89(15)$ \\
\hline
\end{tabular}

especially artery occlusions and treatment-related brain infarctions, were more frequent than expected regardless of the treatment method.

The portion of patients in a poor clinical condition on admission increased to $38 \%$ after 2000 . Although our results are in line with earlier studies demonstrating that an initial poor clinical condition is a factor associated with an impaired outcome, ${ }^{10,22,25,34,41}$ it is encouraging to see that most of our treated patients recovered back at home. It is likely that this increase in poor-grade patients is a consequence of the improved efficacy of medical initial response units and the improved availability of diagnostic tools and increased awareness of the disease, as well as changes in the admission policies of our department. Previously, a larger proportion of these patients might have died outside the neurosurgical unit.

In our series, occlusive treatment-related complications, especially the extent of artery occlusions and treatment-related brain infarctions, were unexpected findings. Previous studies on the treatment of ruptured PCoA aneurysms have mainly reported a moderate number of lacunar infarctions (5\%) and severe bleeding or delayed cerebral vasospasm-related neurological complications (7\%), but only two ICA or MCA occlusions have been documented by the previously largest study and none by the other studies. ${ }^{9,33,37,39}$ We also saw occlusive treatment-related infarctions among initially good-grade patients. These complications occurred throughout the follow-up period. On a yearly basis, artery occlusions were infrequent, but a large patient cohort may pool together and reveal risks that seem minimal in smaller cohorts.

The independent risk factors for an impaired outcome after PCoA aneurysm rupture, in addition to a poor clinical condition, were older age, ICH or SDH after aneurysm rupture, artery occlusion on postoperative angiography, symptomatic delayed cerebral vasospasm, occlusive aneurysm treatment-related brain infarction, and hydrocephalus requiring a shunt. Artery occlusions and treatmentrelated brain infarctions as independent risk factors were new findings. The other factors were mainly in line with the detected risk factors for an impaired outcome after aSAH in previous studies..$^{10,19,22,25,28,34}$ Aneurysm size was not an independent risk factor for a poor outcome in PCoA aneurysm patients, even though it might be for aneurysms at another location. ${ }^{22,28}$ Large or giant PCoA aneurysms were rare, which might affect this result.

\section{Potentially Modifiable Risk Factors for Impaired Outcome} Artery Occlusions

The number of artery occlusions on postoperative angiography was notable $(10 \%$ in the microsurgical treatment group and $8 \%$ in the endovascular treatment group). This finding highlights one of the main goals of treatment: the need to preserve the normal vasculature including the PCoA and to occlude the aneurysm. It seems that efforts should be made to meticulously preserve the PCoA, even those other than fetal PCoAs, as well as the small perforant arteries of the ICA and PCoA. There are publications on PCoA sacrifice that indicate that the risk of infarction seems small in the presence of $\mathrm{P}_{1}{ }^{6,21}$ Our results do not support this view, however. Sacrifice should be considered a suboptimal and potentially risky solution-not only for posterior cerebral artery (PCA) area infarctions, but also for tuberothalamic infarctions. Intraoperative indocyanine green (ICG) videoangiography, intraoperative Doppler ultrasonography, and, especially in complex cases, intraoperative catheter angiography offer useful means of evaluating the patency of adjacent arteries during a microsurgical procedure. ${ }^{4,14,16,32,36}$

\section{Delayed Cerebral Vasospasm and Ischemia}

Although promising results have indicated that with modern treatment, delayed cerebral vasospasm and ischemia may not increase in-hospital mortality in aSAH patients, ${ }^{24}$ it is still a significant cause of morbidity. ${ }^{10} \mathrm{In}$ this study, symptomatic delayed cerebral vasospasm was associated with a twofold risk of impaired outcome at the 1-year follow-up. Efforts to improve the treatment of cerebral vasospasm are ongoing. Several medical therapies and the effect of lumbar drainage are being investigated..$^{2,30}$

\section{Hydrocephalus Requiring a Shunt}

Several earlier publications have shown that chronic post-aSAH hydrocephalus is related to significant morbidity and readmission to the hospital. . $^{1,5,12,18,29,40}$ Potential reasons for an impaired outcome after the need for permanent cerebrospinal fluid diversion have been discussed in a recent publication and included elevated intracranial pressure, injury from catheter misplacement, rehemorrhage, and shunt infections. ${ }^{10}$

According to our results, hydrocephalus requiring a shunt was a complication that was prominent among elder- 
ly patients. The aging brain may be too fragile to make a sufficient recovery from the accumulation of a cerebrovascular burden such as primary aSAH, hydrocephalus, and potential complications or earlier degenerative processes or angiopathies.

\section{Study Limitations}

Even though the retrospective setting should be taken into account when interpreting our results, this study gives an all-inclusive view of patients with ruptured PCoA aneurysms treated at a high-volume center. Very few patients were excluded from this analysis. The study has a strong bias toward the microsurgical treatment method $(83 \%)$ versus endovascular treatment (8\%). As this study period covers three decades, the acceptable standards and requirements for occlusive aneurysm treatment have evolved. Even the clinical condition of hospitalized aSAH patients has changed, and treatment has become more aggressive. Endovascular therapy has been available at our hospital since 1991, but there was a strong tendency to favor clipping during the study period. Nowadays and since 2015 at our institution, about half of ruptured aneurysms are treated via endovascular techniques. However, occlusive treatment-related complications seem to be a challenge regardless of the treatment method. Nowadays, they may be reduced with more versatile and individual treatment strategies.

\section{Conclusions}

Even though most patients made a good recovery after PCoA aneurysm rupture and treatment during the 1st year and only a few were left severely disabled, the procedure-related complications were higher than expected and caused morbidity even among initially good-grade patients. Occlusive treatment of a ruptured PCoA aneurysm seems to be a high-risk procedure, even at a high-volume neurovascular center.

\section{Acknowledgments}

We acknowledge the efforts of Onni Järvinen, $\mathrm{MSc}, \mathrm{PhD}$, a data scientist.

\section{References}

1. Adams H, Ban VS, Leinonen V, Aoun SG, Huttunen J, Saavalainen T, et al: Risk of shunting after aneurysmal subarachnoid hemorrhage: a collaborative study and initiation of a consortium. Stroke 47:2488-2496, 2016

2. Archavlis E, Carvi Y, Nievas M: Cerebral vasospasm: a review of current developments in drug therapy and research. J Pharm Technol Drug Res 2:18, 2013

3. Biesbroek JM, Rinkel GJE, Algra A, van der Sprenkel JWB: Risk factors for acute subdural hematoma from intracranial aneurysm rupture. Neurosurgery 71:264-269, 2012

4. Dashti R, Laakso A, Niemelä M, Porras M, Hernesniemi J: Microscope-integrated near-infrared indocyanine green videoangiography during surgery of intracranial aneurysms: the Helsinki experience. Surg Neurol 71:543-550, 2009

5. Dorai Z, Hynan LS, Kopitnik TA, Samson D: Factors related to hydrocephalus after aneurysmal subarachnoid hemorrhage. Neurosurgery 52:763-771, 2003

6. Endo H, Sato K, Kondo R, Matsumoto Y, Takahashi A,
Tominaga T: Tuberothalamic artery infarctions following coil embolization of ruptured posterior communicating artery aneurysms with posterior communicating artery sacrifice. AJNR Am J Neuroradiol 33:500-506, 2012

7. Engelhardt J, Berge J, Cuny E, Penchet G: Oculomotor nerve palsy induced by internal carotid artery aneurysm: prognostic factors for recovery. Acta Neurochir (Wien) 157:11031111,2015

8. Fisher CM, Kistler JP, Davis JM: Relation of cerebral vasospasm to subarachnoid hemorrhage visualized by computerized tomographic scanning. Neurosurgery 6:1-9, 1980

9. Fukuda H, Hayashi K, Yoshino K, Koyama T, Lo B, Kurosaki Y, et al: Impact of aneurysm projection on intraoperative complications during surgical clipping of ruptured posterior communicating artery aneurysms. Neurosurgery 78:381390, 2016

10. Galea JP, Dulhanty L, Patel HC: Predictors of outcome in aneurysmal subarachnoid hemorrhage patients: observations from a multicenter data set. Stroke 48:2958-2963, 2017

11. Ghods AJ, Lopes D, Chen M: Gender differences in cerebral aneurysm location. Front Neurol 3:78, 2012

12. Greenberg JK, Washington CW, Guniganti R, Dacey RG Jr, Derdeyn CP, Zipfel GJ: Causes of 30-day readmission after aneurysmal subarachnoid hemorrhage. J Neurosurg 124:743-749, 2016

13. Güresir E, Schuss P, Seifert V, Vatter H: Oculomotor nerve palsy by posterior communicating artery aneurysms: influence of surgical strategy on recovery. J Neurosurg 117:904910, 2012

14. Hardesty DA, Thind H, Zabramski JM, Spetzler RF, Nakaji P: Safety, efficacy, and cost of intraoperative indocyanine green angiography compared to intraoperative catheter angiography in cerebral aneurysm surgery. J Clin Neurosci 21:1377-1382, 2014

15. Huhtakangas J, Lehecka M, Lehto H, Jahromi BR, Niemelä M, Kivisaari R: CTA analysis and assessment of morphological factors related to rupture in 413 posterior communicating artery aneurysms. Acta Neurochir (Wien) 159:1643-1652, 2017

16. Hui PJ, Yan YH, Zhang SM, Wang Z, Yu ZQ, Zhou YX, et al: Intraoperative microvascular Doppler monitoring in intracranial aneurysm surgery. Chin Med J (Engl) 126:2424-2429, 2013

17. Hunt WE, Hess RM: Surgical risk as related to time of intervention in the repair of intracranial aneurysms. J Neurosurg 28:14-20, 1968

18. Hütter BO, Kreitschmann-Andermahr I, Gilsbach JM: Cognitive deficits in the acute stage after subarachnoid hemorrhage. Neurosurgery 43:1054-1065, 1998

19. Jabbarli R, Reinhard M, Roelz R, Shah M, Niesen WD, Kaier $\mathrm{K}$, et al: Intracerebral hematoma due to aneurysm rupture: are there risk factors beyond aneurysm location? Neurosurgery 78:813-820, 2016

20. Khan SA, Agrawal A, Hailey CE, Smith TP, Gokhale S, Alexander MJ, et al: Effect of surgical clipping versus endovascular coiling on recovery from oculomotor nerve palsy in patients with posterior communicating artery aneurysms: a retrospective comparative study and meta-analysis. Asian J Neurosurg 8:117-124, 2013

21. Ko JH, Kim YJ: Endovascular strategies for treatment of posterior communicating artery aneurysm according to angiographic architecture: preservation vs. sacrifice of posterior communication artery. Interv Neuroradiol 23:620-627, 2017

22. Koivisto T, Vanninen R, Hurskainen H, Saari T, Hernesniemi J, Vapalahti M: Outcomes of early endovascular versus surgical treatment of ruptured cerebral aneurysms. A prospective randomized study. Stroke 31:2369-2377, 2000

23. Korja M, Kivisaari R, Rezai Jahromi B, Lehto H: Size and 
location of ruptured intracranial aneurysms: consecutive series of 1993 hospital-admitted patients. J Neurosurg 127:748-753, 2017

24. Lantigua H, Ortega-Gutierrez S, Schmidt JM, Lee K, Badjatia N, Agarwal S, et al: Subarachnoid hemorrhage: who dies, and why? Crit Care 19:309, 2015

25. Lehecka M, Niemelä M, Seppänen J, Lehto H, Koivisto T, Ronkainen A, et al: No long-term excess mortality in 280 patients with ruptured distal anterior cerebral artery aneurysms. Neurosurgery 60:235-241, 2007

26. Leivo S, Hernesniemi J, Luukkonen M, Vapalahti M: Early surgery improves the cure of aneurysm-induced oculomotor palsy. Surg Neurol 45:430-434, 1996

27. Molyneux A, Kerr R, Stratton I, Sandercock P, Clarke M, Shrimpton J, et al: International Subarachnoid Aneurysm Trial (ISAT) of neurosurgical clipping versus endovascular coiling in 2143 patients with ruptured intracranial aneurysms: a randomised trial. Lancet 360:1267-1274, 2002

28. Orakdogen M, Emon ST, Somay H, Engin T, Ates O, Berkman MZ: Prognostic factors in patients who underwent aneurysmal clipping due to spontaneous subarachnoid hemorrhage. Turk Neurosurg 26:840-848, 2016

29. Paisan GM, Ding D, Starke RM, Crowley RW, Liu KC: Shunt-dependent hydrocephalus after aneurysmal subarachnoid hemorrhage: predictors and long-term functional outcomes. Neurosurgery [epub ahead of print], 2017

30. Panni P, Fugate JE, Rabinstein AA, Lanzino G: Lumbar drainage and delayed cerebral ischemia in aneurysmal subarachnoid hemorrhage: a systematic review. J Neurosurg Sci 61:665-672, 2017

31. Rankin J: Cerebral vascular accidents in patients over the age of 60. II. Prognosis. Scott Med J 2:200-215, 1957

32. Riva M, Amin-Hanjani S, Giussani C, De Witte O, Bruneau $\mathrm{M}$ : Indocyanine green videoangiography in aneurysm surgery: systematic review and meta-analysis. Neurosurgery 70:556-557, 2017

33. Sanai N, Caldwell N, Englot DJ, Lawton MT: Advanced technical skills are required for microsurgical clipping of posterior communicating artery aneurysms in the endovascular era. Neurosurgery 71:285-295, 2012

34. Sharma P, Mehrotra A, Das KK, Bhaisora KS, Sardhara J, Godbole CA, et al: Factors predicting poor outcome in a surgically managed series of multiple intracranial aneurysms. World Neurosurg 90:29-37, 2016

35. Soni SR: Aneurysms of the posterior communicating artery and oculomotor paresis. J Neurol Neurosurg Psychiatry 37:475-484, 1974

36. Tang G, Cawley CM, Dion JE, Barrow DL: Intraoperative angiography during aneurysm surgery: a prospective evaluation of efficacy. J Neurosurg 96:993-999, 2002
37. Thiarawat $\mathrm{P}$, Jahromi BR, Kozyrev DA, Intarakhao P, Teo MK, Choque-Velasquez J, et al: Microneurosurgical management of posterior communicating artery aneurysm: a contemporary series from Helsinki. World Neurosurg 101:379-388, 2017

38. Wiebers DO, Whisnant JP, Huston J III, Meissner I, Brown RD Jr, Piepgras DG, et al: Unruptured intracranial aneurysms: natural history, clinical outcome, and risks of surgical and endovascular treatment. Lancet 362:103-110, 2003

39. Yasargil MG, Smith RD, Young PH, Teddy PJ: Microneurosurgery: Clinical Considerations, Surgery of the Intracranial Aneurysms and Results. Stuttgart: Thieme, 1984, Vol. 2, pp 71-93

40. Zaidi HA, Montoure A, Elhadi A, Nakaji P, McDougall CG, Albuquerque FC, et al: Long-term functional outcomes and predictors of shunt-dependent hydrocephalus after treatment of ruptured intracranial aneurysms in the BRAT trial: revisiting the clip vs coil debate. Neurosurgery 76:608-614, 2015

41. Zhao B, Yang H, Zheng K, Li Z, Xiong Y, Tan X, et al: Preoperative and postoperative predictors of long-term outcome after endovascular treatment of poor-grade aneurysmal subarachnoid hemorrhage. J Neurosurg 126:1764-1771, 2017

42. Zheng F, Dong Y, Xia P, Mpotsaris A, Stavrinou P, Brinker $\mathrm{G}$, et al: Is clipping better than coiling in the treatment of patients with oculomotor nerve palsies induced by posterior communicating artery aneurysms? A systematic review and meta-analysis. Clin Neurol Neurosurg 153:20-26, 2017

\section{Disclosures}

The authors report no conflict of interest concerning the materials or methods used in this study or the findings specified in this paper.

\section{Author Contributions}

Conception and design: Huhtakangas, Lehecka, Kivisaari. Acquisition of data: Huhtakangas, Lehto, Rezai Jahromi, Kivisaari. Analysis and interpretation of data: Huhtakangas. Drafting the article: Huhtakangas. Critically revising the article: all authors. Reviewed submitted version of manuscript: Lehecka, Lehto, Rezai Jahromi, Niemelä, Kivisaari. Approved the final version of the manuscript on behalf of all authors: Huhtakangas. Statistical analysis: Huhtakangas. Study supervision: Lehecka, Kivisaari.

\section{Correspondence}

Justiina Huhtakangas: Helsinki University Hospital, Helsinki, Finland. justiina.huhtakangas@hus.fi. 